\title{
Lead Site aVR-Dorsal
}

National Cancer Institute

\section{Source}

National Cancer Institute. Lead Site aVR-Dorsal. NCI Thesaurus. Code C135389.

An aug mented unipolar electrocardiog ram limb lead in which the positive electrode is behind the right ear near the right mastoid process and the negative electrode is a combination of the electrode at the hindquarters proximal to the sacrum and the electrode near the apex of the heart (located in the ICS of left 5-6 rib close to the sternum). (CDISC) 